\title{
Identifying the Technical and Teacher Skills Needed by In-Service Teachers to Effectively Teach an Agricultural Mechanics Course in West Virginia
}

Coleton Todd Payne

West Virginia University, ctpayne@mix.wvu.edu

Follow this and additional works at: https://researchrepository.wvu.edu/etd

Part of the Vocational Education Commons

\section{Recommended Citation}

Payne, Coleton Todd, "Identifying the Technical and Teacher Skills Needed by In-Service Teachers to Effectively Teach an Agricultural Mechanics Course in West Virginia" (2021). Graduate Theses, Dissertations, and Problem Reports. 8067.

https://researchrepository.wvu.edu/etd/8067

This Thesis is protected by copyright and/or related rights. It has been brought to you by the The Research Repository @ WVU with permission from the rights-holder(s). You are free to use this Thesis in any way that is permitted by the copyright and related rights legislation that applies to your use. For other uses you must obtain permission from the rights-holder(s) directly, unless additional rights are indicated by a Creative Commons license in the record and/ or on the work itself. This Thesis has been accepted for inclusion in WVU Graduate Theses, Dissertations, and Problem Reports collection by an authorized administrator of The Research Repository @ WVU. For more information, please contact researchrepository@mail.wvu.edu. 


\title{
Identifying the Technical and Teacher Skills Needed by In-Service Teachers to Effectively Teach an Agricultural Mechanics Course in West Virginia
}

\author{
Coleton Todd Payne
}

\begin{abstract}
Thesis submitted to the Davis College of Agriculture, Natural
Resources and Design at West Virginia University

In partial fulfillment of the requirements for the degree of Master of Science in Agricultural and Extension Education
\end{abstract}

\author{
Haley N. Rosson, Ph.D., Chair \\ Jason D. McKibben, Ph.D. \\ A. Preston Byrd, Ph.D. \\ Department of Agriculture and Extension Education
}

\author{
Morgantown, West Virginia \\ 2021
}

Keywords: Technical Skills, Teacher Skills, Agricultural Mechanics, School-Based Agriculture Education

Copyright 2021 Coleton Todd Payne 


\begin{abstract}
Identifying the Technical and Teacher Skills Needed by In-Service Teachers to Effectively Teach an Agricultural Mechanics Course in West Virginia
\end{abstract}

\title{
Coleton Todd Payne
}

Agricultural mechanics remains one of the largest content sections in school-based agriculture education (SBAE). Therefore, in-service and pre-service teachers need to be effective in teaching agricultural mechanics to their students (Burris et al., 2005; Hainline \& Wells, 2019). A number of studies (McKim \& Saucier, 2011; Saucier et al., 2014) have identified the importance of safety in agricultural mechanics laboratories, but not the content skills specifically needed to teach the courses. The only areas of content that most new in-service teachers possess are those of basic woodworking and basic metal working. This study bases its theoretical framework off of the Roberts and Ball (2009) content-based model for teaching agriculture. More specifically, how it impacts the teaching of pre-service teachers in teacher preparation programs under the model's knowledge domain. Using a modified Delphi approach, this study identified the technical and teacher skills needed to effectively teach an agricultural mechanics course. A panel of four agricultural mechanics experts identified 35 items that included 19 technical skills (e.g., welding, etc.) and eight teacher skills (e.g., conditioning tools, etc.). It was concluded that West Virginia SBAE educators should be well versed in all aspects of teaching agricultural mechanics. This is a replication study of Hainline \& Wells (2019), Identifying the Agricultural Mechanics Knowledge and Skills Needed by Iowa School-based Agricultural Education Teachers . 


\section{TABLE OF CONTENTS}

Chapter

Page

I. INTRODUCTION 1

Rationale

1

Purpose/Objectives 3

Definition of Terms 3

II. REVIEW OF LITERATURE 4

Agricultural Mechanics $\quad 4$

Dewey \& Snedden 4

School Based Agricultural Education/Three Circle Model 5

Industry in West Virginia $\quad 8$

Skill Acquisition $\quad 10$

$\begin{array}{ll}\text { Theoretical Foundation } & 12\end{array}$

$\begin{array}{ll}\text { III. METHODOLOGY } & 14\end{array}$

$\begin{array}{ll}\text { Research Design } & 14\end{array}$

Sampling 25

Instrument 16

$\begin{array}{ll}\text { Variables } & 17\end{array}$

Analysis 17

Alternatives 18

$\begin{array}{ll}\text { Controlling Threats to Validity } & 18\end{array}$

Internal Validity 18

External Validity 18

Limitations and Assumptions 19

$\begin{array}{ll}\text { IV. RESULTS } & 21\end{array}$

$\begin{array}{ll}\text { Introduction } & 21\end{array}$

$\begin{array}{ll}\text { Purpose and Objectives } & 22\end{array}$

Methods and Procedures $\quad 22$

Instrument 22

Population $\quad 23$

Data Collection $\quad 24$

Round One 24 


$\begin{array}{cc}\text { Round Two } & 25 \\ \text { Round Three } & 25 \\ \text { Data Analysis/Results } & 26 \\ \text { Round One } & 26 \\ \text { Round Two } & 27 \\ \text { Round Three } & 31\end{array}$

V. CONCLUSION 32

Discussion/Implications $\quad 32$

$\begin{array}{ll}\text { Recommendations } & 34\end{array}$

$\begin{array}{ll}\text { REFERENCES } & 36\end{array}$

APPENDICES

Appendix A - IRB Approval Letter $\quad 42$

Appendix B - Survey Cover Letter $\quad 45$

Appendix C - Survey Round One $\quad 47$

Appendix D - Survey Round Two 51 


\section{LIST OF TABLES}

Table

4.1 Study Demographics

4.2 Round One: Technical and Teacher Skills Identified

4.3 Round Two: Consensus by Panel

4.4 Items Rated 5 or 6
Page

27

30

32

34 


\section{LIST OF FIGURES}

Figure $\quad$ Page

Figure 2.1. Roberts \& Ball model for Content \& Context 18 


\section{CHAPTER I}

\section{INTRODUCTION}

In today's school-based agriculture education (SBAE), teachers use a context rich environment that teaches vocational skills, along with knowledge from various other content areas, to provide an integrated approach to curriculum (Roberts \& Ball, 2009). John Dewey first proposed the idea of specific skill acquisitions through specialized facilities, in which students would take knowledge learned and apply it to concepts in a hands-on approach (Dewey, 1938; Roberts \& Ball, 2009). Historically, agriculture mechanics have served as the staple of those specialized facilities in which applied concepts could be learned (Hainline \& Wells, 2019; Twenter \& Edwards, 2017). Therefore, mechanics teachers should be prepared to teach those skills effectively (Hainline \& Wells, 2019). However, in most cases, new in-service teachers find that they are not competent in areas outside of basic woodworking and metal fabrication (Hainline \& Wells, 2019; Newcomb, 1974). Burris, Robinson, \& Terry (2005) found that first year SBAE teachers had a high personal efficacy, but rated low on content efficacy, especially in mechanical aspects. In order to effectively teach mechanical skills to students, the teachers must, in-turn, be efficient in those skills.

\section{Rationale}

Laboratory instruction is a fundamental part of school based agricultural education (SBAE) (Oomes \& Jurshak, 1978; Roberts \& Ball, 2009; Twenter, 2017). In SBAE, the laboratory serves to connect the teachings of the classroom to the skills used in real world applications (Twenter \& Edwards, 2017). Lab settings come in many forms, whether it be 
livestock barns, greenhouses, or land labs; all serve to connect the usable skills needed to make career ready students (Twenter \& Edwards, 2017). The largest and most common lab setting is the mechanics shop (Hainline \& Wells, 2019; Shoulders \& Meyers, 2012). However, it's this area of emphasis that many agriculture teachers feel they lack the most knowledge in (Hainline \& Wells, 2019). For years, mechanics has been a staple of SBAE (Shoulders \& Meyers, 2012) and research has shown that new in-service teachers find it challenging to step into the roles of mechanical teachers and don't feel confident in their efficiency to teach it (Hainline \& Wells, 2019).

When most people think of agriculture mechanics, they think in limited terms of welding and metal fabrication, when the reality is that mechanics cover a wide variety of technical skills (Hainline \& Wells, 2019). They include woodworking, construction, metal fabrication, welding, engines, and even higher learning aspects of applied mathematics and renewable energies (Hainline \& Wells, 2019). Mechanics teachers have to be some of the most flexible teachers in the building when it comes to curriculum (Wells et al., 2013). They have to be able to make solid weld with a stick welder, know how to lay out rafters for a building, and how to rebuild a small gas engine (Hainline \& Wells, 2019). They need these skills of application as well as the safety knowledge to ensure the well-being of all the students. The question at hand is whether teachers feel capable of teaching those skills? 


\section{Purpose and Objectives}

The purpose of this study is to examine the skills needed by SBAE teachers to effectively instruct their students in agricultural mechanics. To achieve this, the following objectives were created:

1. Identify the important agricultural mechanics knowledge and skills needed by West Virginia SBAE teachers; and

2. Determine the important agricultural mechanics "teacher skills"/laboratory management skills needed by West Virginia SBAE teachers.

\section{Definition of Terms}

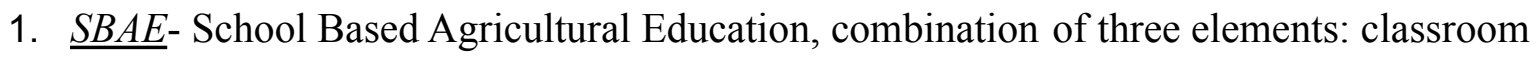
instruction, FFA, supervised agricultural experience program (National FFA, 2021).

2. Facilities- Places outside the classroom where practical application skills can be learned and practiced (Shoulders \& Myers, 2012).

3. Mechanics- Knowledge on small engines, carpentry, metal fabrication, welding, wood working, electricity, power engines, and applied mathematics (Oomes \& Jurshak, 1978).

4. Weld- Bonding of two metal pieces together using heat and filler material (TWI, n.d.).

5. In-Service Teacher- Certified agricultural teachers working in agriculture programs.

6. Pre-Service Teachers- Students in teacher preparation programs at colleges and universities. 


\section{CHAPTER II}

\section{REVIEW OF LITERATURE}

\section{Agricultural Mechanics}

Agriculture mechanics has been found to be one of the most important aspects of successful agriculture programs (Kotrlik \& Drueckhammer, 1987). With all agriculture mechanics shops across the country, safety is the number one priority (McKim \& Saucier, 2011; Saucier, Vincent \& Anderson, 2014). Previous research has been done on the effects of qualified teachers to effectively and safely manage the laboratory space (McKim \& Saucier, 2011; Saucier et al., 2014). Laboratory instruction offers students a space for hands-on learning and a place for skills to be applied (Oomes \& Jurshak, 1978). This study looks at the content skills needed, rather than the safety and management skills. However, safety and management skills could fall under the skills deemed necessary as a whole. Proper management of mechanical laboratories is key to having an effective learning facility and quality views of the program itself (Johnson \& Schumacher, 1989). Teachers need to be flexible and knowledgeable in both subject content and management (Hainline \& Wells, 2019).

\section{Dewey \& Snedden}

The early 20th century saw a drastic shift in the educational ideas and systems throughout the United States (Roberts \& Ball, 2009). This was caused by the changing from an agrarian society to a growing industrial powerhouse, thus creating a need for more skilled labor (Hyslop-Margison, 1999). Two men by the name of John Dewey and David Snedden began a 
war of ideas on how exactly vocational education, the precursor to today's Agriculture Education model, should be structured (Roberts \& Ball, 2009). Snedden insisted that vocational education should be driven by the industry standards and needs (Hyslop-Margison, 1999). He proposed that this would be achieved by having the students take specific skill driven courses, such as metal working or electricity, where they would learn skills and knowledge that was needed by specific industry jobs. Therefore, the main purpose of vocational education was to meet industry needs and create limited intellectual but highly specific skilled laborers (Hyslop-Margison, 1999).

Dewey, on the other hand, argued that students should be active learners and consumers of knowledge to ensure that they could be effective members of society and not be locked into a predestined social category. He argued that vocational education should be part of a comprehensive curriculum that taught not only skill acquisition, but overarching knowledge of many subjects (Hyslop-Margison, 1999). In essence, Snedden argued that the education of the student should rise to meet the industry needs and social attitudes towards the workforce, whereas Dewey argued that the education should meet the needs of the student and prepare them not only as skilled workers but also as overall learners (Hyslop-Margison, 1999).

\section{SBAE/Three Circle Model}

There is a plethora of legislation that made a difference in the agricultural world; none more so to agriculture educators than the Smith-Hughes Act of 1917 (Hillison, 1987). Hillison (1987) explains that, while the act formally installed vocational education, or what is now called School-Based Agricultural Education, it was not the true beginning. In actuality, agriculture in the classroom started about 20 years prior. In the years leading up to the passing of the act, there 
was a magnitude of enthusiasm and push for agriculture and skills teaching, but it was matched by the number of questions and unknowns (Hillison, 1987). Some of the earliest forms of agricultural education came as "nature study," where elementary school teachers would allow their students to see and learn about the world around them, whether in rural or urban schools (Hillison, 1987).

One of the main questions that plagued the early years was how and where to get teachers. The first place to look was the Land-Grant Universities of the 1862 Morrill Act (Hillison, 1987). These institutions offered the most direct approach through their teacher preparation programs (Hillison, 1987). Eventually, it came down to four categories that teachers could come from: nature study teachers, agricultural college graduates, high school science teachers, and people raised on farms (Hillison, 1987). The act detailed that all participating states were to use federal funds to establish vocational teachings in schools and state level boards to supervise the schools and act as a go-between of the federal government (Steffes, 2020).

Even though places had been identified to attain teachers, keeping the flow of teachers coming in and out of jobs was another problem (Eck \& Edwards, 2019). Shortage of teachers has plagued SBAE from its beginnings and continues to this day (Eck \& Edwards, 2019). This has caused many SBAE programs to cut back on teaching efforts and, in some cases, closure of the entire program (Eck \& Edwards, 2019). Eck and Edwards (2019) sought to outline and document the history of teacher shortage in agriculture education, as well as the efforts to address the problem. The first big attempt to resolve the issue came in a 1964 study that sought to determine the supply and demand problems for, then, vocational education teachers (Eck \& Edwards, 
2019). Following the first year, the study became an annual research objective that sought to not only identify places of large shortage, but to also identify any solutions to the problem (Eck \& Edwards, 2019). These would become known as supply and demand studies and would last from 1965-1995, later becoming three year studies until 2009 (Eck \& Edwards, 2019). The major finding that Eck and Edwards (2019) detailed is that attrition was the highest among teachers in the one to three years of teaching and drastically declined after the five year mark. Over the years, many ideas have come forth to try and recruit more people to the profession. These have included greater promotion within high schools, incentives such as scholarships, and alternative teaching certification (Eck \& Edwards, 2019).

Todays' agricultural education model is based around what is called the Three Circle Model of agricultural education (Shoulders \& Toland, 2017). The model is composed of three equal circles consisting of classroom instruction, supervised agricultural experiences (SAE), and FFA (Shoulders \& Toland, 2017). The model shows how SBAE uses three distinct modes of education to form the comprehensive educational experience (Shoulders \& Toland, 2017). Classroom is the combination of hands-on activities, coupled with textbook learning, and is arguably the most effective and needed of the components (Shoulders \& Toland, 2017). The next component, SAE, gives the students the ability to apply the knowledge learned in the classroom to the real world through applications at work or at home (Shoulders \& Toland, 2017). The last component is FFA. The National FFA Organization provides students the opportunity to develop leadership skills, focus on personal growth, and achieve career success (Shoulders \& Toland, 2017). FFA is an intracurricular organization, meaning part of the curriculum, as opposed to extracurricular, that provides an award structure for the individual, as well as the chapter 
(Shoulders \& Toland, 2017). While the model is presented with all three circles as equal, Torres et al. (2008) found that teachers do not place equal emphasis on all three components. They found that new teachers placed more importance on classroom instruction and the content. Experienced teachers will put more effort into teaching related activities outside of the classroom instruction to further their teaching methods (Torres et al., 2008).

\section{Industry In West Virginia}

Historically, the agriculture industry in West Virginia has seen boom and bust years. In the late 19th and early 20th centuries, West Virginia was a haven of agriculture producers (Brannon, 2018). However, once the industrial revolution started to make an impact on the agriculture industry, that all changed (Brannon, 2018). West Virginia agriculture has generally been made up of the beef, milk, vegetable crop, and feed crop industries (Brannon, 2018). Over time, all of those industries have diminished extensively (Brannon, 2018). At one time, the state boasted over 60 milk distribution plants; now that number has dwindled to one (Brannon, 2018).

The landscape is much different today, however. Today, the majority of West Virginia farms are considered family farms or small farms with an average size of 176 acres and the average age of farmers at 61 years (Brannon, 2018). While the job market for production agriculture isn't the powerhouse it used to be, West Virginia does offer jobs in the industrial agriculture side. West Virginia is home to three chicken and turkey processing plants, including Aviagen Turkeys in Monroe County, as well as Pilgrims Pride and Perdue in Hardy County (West Virginia Department of Commerce, n.d.). 
One of the largest industries in West Virginia, the coal industry, dates back to the decades leading up to the American Revolution (National Coal Heritage Area \& Coal Heritage Trail, n.d.). By 1800, coal was being shipped from then, southern western Virginia (now southern WV), to the major cities across the eastern seaboard to burn in everything from peoples' home stoves to industrial plants (National Coal Heritage Area \& Coal Heritage Trail, n.d.). It wasn't until the mid 1800's when the first industrial coal boom hit because of the development of railroads (National Coal Heritage Area \& Coal Heritage Trail, n.d.). These booms were on-again off-again through the 1980's; however, it looks like the golden days of coal mining are long behind us (National Coal Heritage Area \& Coal Heritage Trail, n.d.). That being said, the West Virginia Coal Association reported in 2010 that the industry accounted for more than 20,000 direct mining jobs and over 70,000 indirect jobs. West Virginia is the second largest coal producing state in the country and ships to more than 30 other nations worldwide (West Virginia Coal Association, 2010).

Much like the coal industry, the timber industry has its roots in a time when West Virginia was considered the frontier (West Virginia State Museum Education, n.d.). It wasn't until the years following the American Civil War that industry really became a powerhouse in the state and surrounding areas (West Virginia State Museum Education, n.d.). The development of steam powered sawmills and new ways of transporting the lumber made West Virginia the nation's third largest producer between 1870 and 1920 (West Virginia State Museum Education, n.d.). Today, the timber industry generates $\$ 3.2$ billion annually and boasts more than 30,000 jobs (West Virginia Division of Forestry, n.d.). These jobs include everything from equipment and chainsaw operators on the logging side, to the value-added product producers such as split rail fence, 
engineered lumber manufacturers, and furniture builders (West Virginia Division of Forestry, n.d.).

West Virginia is also home to a plethora of other industries. including oil and gas, automotive, manufacturing, and energy (West Virginia Department of Commerce, n.d.). The state sits atop the Marcellus and Utica Shale gas fields, which continues to draw in large numbers of gas companies (West Virginia Department of Commerce, n.d.). Oil and gas accounts for more than 70,000 jobs that include employment by the gas company, as well as equipment operators and welders to build the infrastructure and well sites (Alvaro, 2019). However, this is an up and down job market that fluctuates year-to-year and presidential administration to administration (Alvaro, 2019).

West Virginia is also home to a number of manufacturing companies, including DuPont, Kingsford Charcoal, and The Homer Laughlin China company (West Virginia Department of Commerce, n.d.). West Virginia is also home to many automotive manufacturers, including industry titans Toyota and NGK Sparkplugs (West Virginia Department of Commerce, n.d.). The Toyota engine plant in the town of Buffalo produces over 5,000 engines a month and employs a few hundred people (Associated Press, 2021).

\section{Skill Acquisition}

The basis of skill acquisition comes from what is called the Skill Acquisition Theory. Skill Acquisition Theory is the claim that the learning of skills is similar to all peoples and every set of skills being learned (DeKeyser et al., 2007). DeKeyser et al. (2007) wrote, 
"The learning of a wide variety of skills shows a remarkable similarity in development from initial representation of knowledge through initial changes in behavior to eventual fluent, spontaneous, largely effortless, and highly skilled behavior, and that this set of phenomena can be accounted for by a set of basic principles common to the acquisition of all skills" (pg. 95).

In the beginning, a student will show interest in the skill area and may present a limited knowledge on the skill (DeKeyser et al., 2007). After that, the student will move into the "acting on" stage of skill acquisition. This is the stage where the student will obtain as much knowledge as they can, including how to develop the knowledge into "how-to-do" knowledge (DeKeyser et al., 2007). Eventually, through a large amount of practice, the student will take this knowledge and turn it into applied behavior (DeKeyser et al., 2007). Once this stage is reached, the student now enters a stage of almost automaticity and the skill in question becomes second nature and observable, correct production of the skill (DeKeyser et al., 2007).

Dreyfus (2004) outlined a five stage timeline that all students go through in skill acquisition. These stages are (1) Novice, (2) Advanced Beginner, (3) Competence, (4) Proficiency, and (5) Expertise (Dreyfus, 2004). There is no clear cut way to determine which stage the student will be in at a given time but a good estimate can be made through the level of context at which the student comprehends (Dreyfus, 2004). Inevitably, the expert will be able to react almost entirely off of instinct, where the earlier levels will have to consciously examine and think about what they are doing (Dreyfus, 2004). 


\section{Theoretical Foundation}

Roberts and Ball (2009) proposed a philosophical question to compare the differences between the two premises on which agriculture education in the United States is founded on, that of David Snedden and John Dewey. In the early 1900's, Snedden proposed the idea of using a content-based approach to agriculture education, where students learn specialized skills separate from general academic learning in order to develop a skilled workforce. On the other hand, John Dewey suggested a context-centered learning style to agriculture education in which students learn applicable skills with integrated knowledge from other subjects to make well-rounded lifelong learners (Roberts \& Ball, 2009). Roberts and Ball produced a theoretical framework that combined the two theories (Fig. 2.1). Their framework demonstrated how the agriculture industry standards drove curriculum to make skilled, lifelong learners.

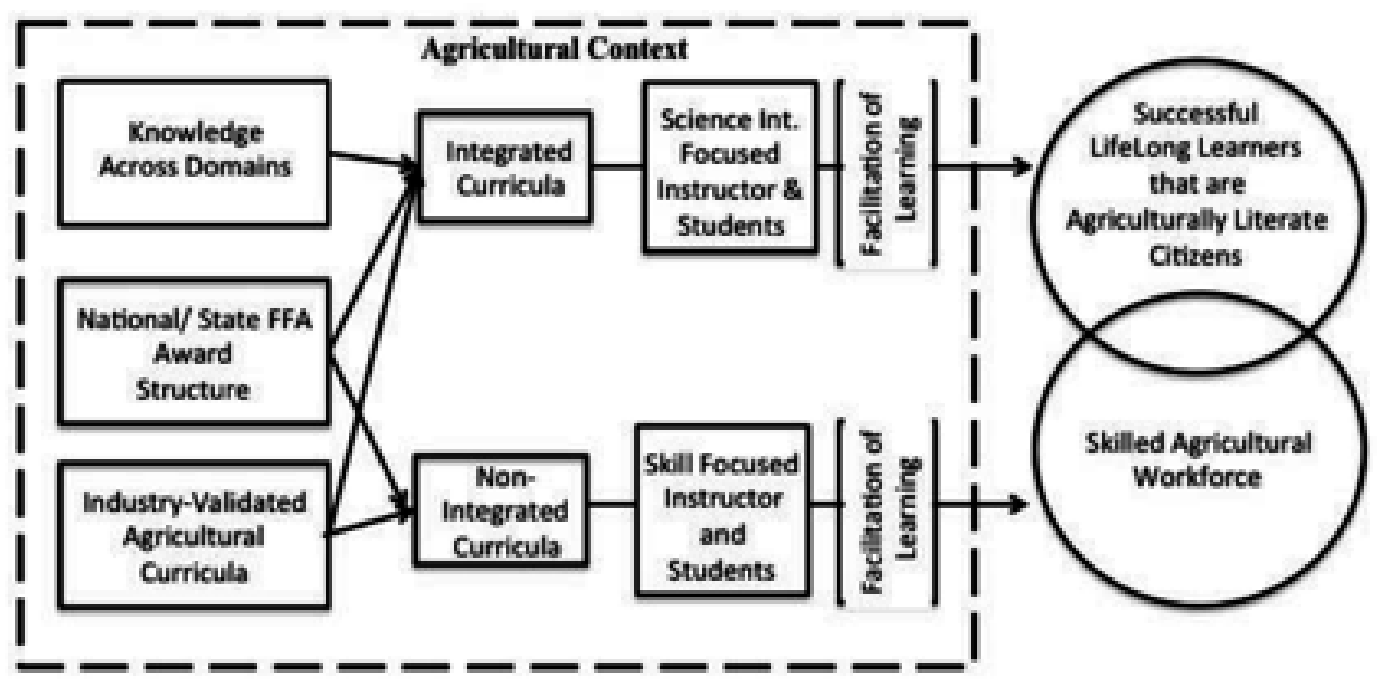

Figure 2.1: Roberts \& Ball model for Content \& Context. Reprinted from Secondary Agricultural Science as Content \& Context for Teaching, Journal of Agriculture Education, 50(1), 81-91, by Grady Roberts \& Anna Ball, copyright 2009. Reprinted with permission. 
The model sets out to show how knowledge, award structure, and industry validated curricula drive the teaching of students. The one place that it doesn't offer information on is the teaching of teachers. This would fall under the knowledge across domains, being that the teacher is someone who provides information to the student. 


\section{CHAPTER III}

\section{METHODOLOGY}

\section{Research Design}

A modified Delphi approach was used to obtain data on the subject of this study. The Delphi method has its origins in the ancient Oracle of Delphi in Greece, where people would seek counsel on everyday matters (Woundenberg, 1991). The objective is to reach consensus on the matter at hand by using subject matter experts (Hainline \& Wells, 2019). The use of Delphi came into practice in the 1960's by the RAND corporation in which they sequestered experts in a room until they reached consensus (Woundenber, 1991). However, some argue against the use of the locked door method. They make the point that by having the experts together, their choices can be influenced by their peers (Woudenberg, 1991). For this study, a modified Delphi approach was utilized, where the experts are asked to answer a survey, anonymous to the other participants but not to the researcher, in order to limit the answers to the opinions of the individual solely. A three-round Delphi technique was applied to create a list of the most important mechanical skills.

In order to find the experts and create the panel, a snowball technique was used. The snowball sampling method is one that uses participants to nominate other potential candidates to create a panel of experts (Goodman, 1961). Candidates had to meet the following criteria: (1) have at least three years of experience teaching agricultural mechanics content in the state of West Virginia; (2) have taught agricultural mechanics courses within the last ten years; and (3) 
have experience with training an FFA Agricultural Mechanics Career Development Event (CDE) team in the last ten years.

Once the panel was identified and vetted, a web-based questionnaire was sent out. The first round consisted of two open-ended questions: "What technical agricultural mechanics knowledge and skills are needed by agricultural education teachers to successfully teach agricultural mechanics courses in West Virginia?" and "What laboratory management "teacher skills" (i.e., setting up an oxy-acetylene system for use, changing a table saw blade, etc.) are needed by agricultural education teachers to successfully teach agricultural mechanics courses in West Virginia?" The second round consisted of a list of the skills found by the panel, where duplicates were tossed out, in which the experts were asked to rate them using a Likert-Type scale: $(1$ = Strongly disagree; 2 = Disagree; 3 = Slightly disagree; 4 = Slightly agree $; 5=$ Agree; $6=$ Strongly agree). Round three consisted of a list of the top-rated skills, 5 or above, that reached consensus by the group. The experts were again asked to rank the highest rated skills and reach consensus. The data reported was how high each skill was rated. However, due to the lack of participants and continuing participation from those who did, a third round was deemed unnecessary and not sent out.

\section{Sampling}

In order to create a panel of experts for the study, experienced SBAE mechanics teachers within the state of West Virginia were sought. The snowball sampling technique was employed to find these qualified individuals. Snowball sampling helps to identify experts at a faster pace and also creates a panel that is seen as equals across the board (Goodman, 1961). The 
participants had to meet a three-phased criteria to be used in the study; (1) have at least three years of experience teaching agricultural mechanics content in the state of West Virginia; (2) have taught agricultural mechanics courses in the last ten years; and (3) have experience with training an FFA Agricultural Mechanics Career Development Event (CDE) team in the last ten years. In order to form the panel of experts, the 2018-2019 West Virginia State FFA President was contacted and asked to provide names for the study. He was able to compile a list of 15 people to participate in the study. The researchers concluded that this number was a sufficient and practical sample size for the study.

\section{Instrument}

A three round Delphi method was used to obtain data for the study. The first round consisted of two questions asking the participants to describe their demographics and what skills they deemed important for effectively teaching agriculture mechanics in the state of West Virginia. The second round asked the experts to rate the skills found using a 6-point Likert-type scale: $(1=$ Strongly disagree; 2 = Disagree; $3=$ Slightly disagree; 4 = Slightly agree $; 5=$ Agree; $6=$ Strongly agree). Round three asked the experts again to rate the highest rated skills from round two using the same Likert scale. The three rounds helped to give a clear sense of which skills were deemed most important. The Likert-type scale gave the panel the same voting format so that all votes cast were easily understood and there was no room for interpretation of how someone voted. 


\section{Variables}

The experiences of the experts were a considerable variable to be encountered in this study. The range of years teaching can be quite large, meaning that some experts have much more experience in this, while others could be very new in their careers. Their learning experiences and personal experiences are a huge driving force behind the way they vote on the individual skills and the ones they deem important. Another variable is the region in which they teach. There is an overarching basis of what is being taught in mechanic shops across the country, but, just like the differences across the nation, there are subtle differences in how the curriculum is taught in different parts of the state.

\section{Analysis}

The first-round responses by the experts were organized into a list. Duplicate responses were removed and only used on the list once. Double responses were split into individual items. Frequency and percentages of the answers on the two Likert-Type scales were computed using the Statistical Package for the Social Sciences v. 27.0 analysis pack. Items from the entire list that reached consensus $(\geq 75 \%)$, or a rating of 5 or 6 , were moved on to the second round, along with unique items in the mid-range $(\geq 50 \%-\leq 74 \%)$. Items in the lower range $(\leq 50 \%)$ were removed from further examination. Due to the decrease in participation from round one to round two, the third round could not be completed. Therefore, analysis occurred after the second round of data collection. 


\section{Alternatives}

An alternative to this approach of the study would be a true locked door Delphi, but feasibility and participation would be large hurdles to overcome. Another alternative would be an observation approach where the researcher would choose what skills are important by watching a teacher in the lab. This poses the problem that the skills deemed important are based solely off of the researchers views and not by multiple people. Also, an interview style could be done. This would require a significant portion of time and money from the researcher to accomplish this.

\section{Internal/External Validity}

Drost (2011) defines validity as the meaningful relationship between the research question and the findings of it. From that, there are two sections of validity: internal and external. Internal validity is the validity of the research itself (Drost, 2011). More so, do the results accurately represent the question based on factors at hand. Internal validity has many threats including history, maturation, testing, instrument used, mortality, compensation, rivalry, and demoralization (Drost, 2011). Heale \& Twycross (2015) break down validity into three types: content validity, construct validity, and criterion validity. Content validity seeks to find if the instrument used adequately covers the content with respect to the variable (Heale \& Twycross, 2015). Construct validity is whether the answers from the survey can accurately be related to the concept at hand (Heale \& Twycross, 2015). Criterion validity is if any other instrument can measure the same variable (Heale \& Twycross, 2015).

In an effort to control internal validity for this study, many factors were considered. To combat factors such as maturation, mortality, and demoralization, this study was built to be 
anonymous, short (three weeks) in overall time length, and short in time spent answering questions (10 minutes). This study offered no compensation in an effort to make sure the candidates were truthfully and accurately creating and ranking their responses based on their own desires. The survey instrument used in this study is a Likert-type scale. The correlation of the answers between multiple participants serves to provide instrument validity.

External validity is the generalization of the answers from one group to another (Drost, 2011). A good sample population should find answers that will accurately be applicable to the entire population (Drost, 2011). In order to meet external validity, this study uses the population of West Virginia SBAE teachers. In 2018-2019, the West Virginia FFA Association reported 109 SBAE educators in the state. For this study, a sample of 15 SBAE teachers was compiled in an effort to collect data that could be implied to the entire population. These 15 were considered to be experts in the agriculture mechanics field and met the criteria for this study.

\section{Limitations \& Assumptions}

The Delphi method study was used in this study. The reliability of a Delphi study served as a limitation to the study (Hainline \& Wells, 2019). By using the modified Delphi study, an assumption is made that the experts found were indeed highly qualified by their years of experience. It was assumed that the experts had considerable knowledge in the subject of agriculture mechanics. Another limitation of this study is that the Delphi has no hard rules or standards, meaning that the experts didn't have to meet any guidelines to participate in the study other than deemed expertise. Participation also served as a limitation. Panel size can range from 
4 to 400, but for this study, a panel size between 5-15 was optimal (Goodman, 1961). A small panel size was applicable to this study due to the fact that the targeted population is small. 


\section{CHAPTER IV}

\section{RESULTS}

\section{Introduction}

Agricultural mechanics has been, and continues to be, one of the highest enrollment courses within agriculture education (Burris et al., 2005). Agricultural education teachers identified the importance of developing mechanical skills and competencies in pre-service programs (Hainline \& Wells, 2019). Current SBAE educators place a large emphasis on student safety (McKim \& Saucier, 2011; Saucier et al., 2014). The purpose of this study was to examine what content areas and skills were deemed valuable in teaching agricultural mechanics. Laboratory instruction offers a place for students to apply the knowledge they gain in the classroom to hands-on work in a safe and controlled environment (Oomes \& Jurshak, 1978). Teachers have to be well versed and flexible in their content areas and management skills of the laboratory space (Hainline \& Wells, 2019). Within today's agriculture education model, classroom and laboratory time make a significant portion of the three-circle model (Shoulders \& Toland, 2017).

Historically, agricultural mechanics have been one of the largest content areas within the laboratory portion of SBAE (Hainline \& Wells, 2019; Twenter \& Edwards, 2017). Research shows that most new SBAE educators feel their competency and efficacy levels in agricultural mechanics are low (Newcomb, 1974; Burris et al., 2005; Hainline \& Wells, 2019). Mechanical SBAE teachers have to be flexible, knowledgeable, and comfortable in teaching the large number 
of skills that is required in an agricultural mechanics course (Wells et al., 2013; Hainline \& Wells, 2019).

\section{Purpose and Objectives}

The purpose of this study was to determine what technical and teacher skills are deemed most necessary to teach agricultural mechanics. To achieve this, the following objectives were created:

1. Identify the important agricultural mechanics knowledge and skills needed by West Virginia SBAE teachers; and

2. Determine the important agricultural mechanics "teacher skills"/laboratory management skills needed by West Virginia SBAE teachers.

\section{Methods and Procedure}

\section{Instrument}

The survey instrument used in this study was a three-round Qualtrics online survey. The first round consisted of two open-ended questions: "What technical agricultural mechanics knowledge and skills are needed by agricultural education teachers to successfully teach agricultural mechanics courses in West Virginia?" and "What laboratory management "teacher skills" (i.e., setting up an oxy-acetylene system for use, changing a table saw blade, etc.) are needed by agricultural education teachers to successfully teach agricultural mechanics courses in West Virginia?" The second round was a list compiled of the skills found by the panel in which the experts were asked to rate them using a Likert-Type scale: $(1=$ Strongly disagree; $2=$ 
Disagree; 3 = Slightly disagree; 4 = Slightly agree; $5=$ Agree; $6=$ Strongly agree). Round three was a list of the top-rated skills, 5 or above, that reached consensus by the group. The experts were again asked to rate the highest rated skills and reach consensus. The data reported was how high each skill was rated.

\section{Population}

The population evaluated for this study was the agricultural mechanics teachers in West Virginia. In 2018-2019, the West Virginia FFA Association reported 81 active programs throughout the state, but not all have an agricultural mechanics program. Since this is a modified Delphi approach, the panel can range to any number, but should be accurate to the population size (Goodman, 1961). A list of 15 possible participants $(n=15)$ was compiled to serve as an accurate representation of the population. The participants ranged in age, gender, years teaching, and types of mechanical programs (Table 4.1). However, only four participants responded $(n=4)$ to the first round and only those four participants can be reported on.

Table 4.1

Panel of Experts

Demographics $(n=4)$

\begin{tabular}{lccc}
\hline Gender & Age & Years Teaching & Type of Program \\
\hline Female & $50+$ & $12-17$ & Metal \& Wood \\
Male & $40-49$ & $12-17$ & Metal \& Mechanics \\
Male & $50+$ & $6-11$ & Metal \& Wood
\end{tabular}




\section{Data Collection}

Round one: An email was sent out to the 15 possible participants to begin this study. The email contained a detailed description of the study and the modified Delphi approach, as well as an in depth cover letter and link to the survey. The information in the cover letter and the email sought to provide transparency and reduce participation loss. The starter email also detailed the timelines for when the rounds would be sent out and when the survey should be completed. All surveys were built in and distributed by the Qualtrics web-based survey platform.

The first round of the survey asked the participants to list any and all technical and teacher skills they deemed necessary in teaching an agricultural mechanics course in the state of West Virginia. The open-ended questions were as follows: “What technical agricultural mechanics knowledge and skills are needed by agricultural education teachers to successfully teach agricultural mechanics courses in West Virginia?" and "What laboratory management "teacher skills" (i.e., setting up an oxy-acetylene system for use, changing a table saw blade, etc.) are needed by agricultural education teachers to successfully teach agricultural mechanics courses in West Virginia?" Also, the first round consisted of a series of multiple choice and short-answer demographic questions which sought to find information such as age, background, and teaching experience of participants. Of the 15 possible participants that the survey was sent to, four participants responded. They identified a total of 33 technical skills they thought to be 
necessary in teaching agricultural mechanics. Once the duplicates were taken out of the list, a total of 19 skills were reported for analysis. They also identified 16 teacher skills they deemed necessary. Again, the duplicates were removed, leaving eight items to use for analysis.

Round two: The second round of the web-based survey instrument was sent via email to the four participants from the first round containing information on when to have it finished by and the link to the survey. Two $(n=2,50 \%)$ of the four agricultural mechanics teachers who participated in the first round participated in the second round. The 35 technical and teacher skills gathered in the first round of the Delphi survey were used to make up the list for the second round. The list was accompanied by a six point Likert-type scale $(1=$ Strongly disagree; $2=$ Disagree $; 3=$ Slightly disagree $; 4=$ Slightly agree $; 5=$ Agree $; 6=$ Strongly agree $)$. The panel of experts were asked to rate each topic based on the importance to teaching an agricultural mechanics course. Topics that received a score of five (Agree) or six (Strongly agree) by the experts were considered to have reached consensus.

Round three: By research design, a third and final round was set up to take the topics that scored a five (Agree) or six (Strongly agree) in round two and have them reevaluated by the panel. The items that again received a score of five (Agree) or six (Strongly agree) would then be considered to be the most important in teaching agriculture mechanics through the consensus by the panel. However, due to the reduced participation from round one to round two, the researchers concluded that a third round was not applicable to the study anymore. Therefore, topics from round two that received a score of five (Agree) or six (Strongly agree) by the two experts were considered consensus. Data analysis was then conducted after round two. 


\section{Data Analysis/Results}

\section{Round One}

Data were analyzed using Statistical Package for the Social Sciences v. 27.0. Round one of collection found a total of 33 technical items and 16 teacher skills from four participants.

Those lists were trimmed down to eliminate duplicate responses, leaving 19 technical and eight teacher skills (Table 4.2).

Table 4.2

Round One: Technical and Teacher skills

Identified $(n=4)$

Technical Skills $\quad$ Teacher Skills

Oxy-Acetylene Torch

Tool Usage

SMAW Welding

Tool Repair

MIG Welding

Machine Repair

TIG Welding

Machinery Operation

Metal Fabrication

Replacing Worn Equipment

Diesel Engine

Safety

Small Gas Engine

Supervision

Electrical Wiring

Skill Knowledge 


\section{Electrical Principles}

Masonry

Soldering

Plumbing

Carpentry

Structural Theory

Mechanical Repair

Tool Identification

Tool Conditioning

Measuring

Safety

\section{Round Two}

The combination of technical skills and teacher skills made up a list of 35 skills to be rated by the agricultural mechanics teachers. At the end of round two, a total of 11 items reached a consensus of $100 \%$. It is worth noting that since there were only two participants in round two, the remaining 24 items, by default, had a consensus rating of 50\%. Also, five of the 11 consensus 
items were rated at five (Agree) or six (Strongly agree). The remaining six items had a score from one (Strongly disagree) to four (Slightly agree) (Table 4.3).

Table 4.3

Round Two: Consensus by Panel

$(n=2)$

Mechanics Topics \% Agreement

Oxy-Acetylene Torch

100

SMAW Welding

$50 *$

MIG Welding

$50 *$

TIG Welding

100

Metal Fabrication

$50 *$

Diesel Engine

100

Small Gas Engine

$50 *$

Electrical Wiring

$50 *$

Electrical Principles

50 *

Masonry

$50 *$

Soldering

$50 *$ 
$\begin{array}{ll}\text { Plumbing } & \text { 50* }\end{array}$

$\begin{array}{ll}\text { Carpentry } & 100\end{array}$

$\begin{array}{ll}\text { Structural Theory } & 100\end{array}$

$\begin{array}{ll}\text { Mechanical Repair } & 100\end{array}$

Tool Identification 50*

Tool Conditioning $\quad 100$

$\begin{array}{ll}\text { Measuring } & 100\end{array}$

$\begin{array}{ll}\text { Safety } & 100\end{array}$

$\begin{array}{ll}\text { Tool Usage } & 100\end{array}$

Tool Repair 50*

Machine Repair 50*

Machinery Operation $\quad 100$

Replacing Worn Equipment 50*

$\begin{array}{ll}\text { Safety } & 50 *\end{array}$

Supervision 50*

Skill Knowledge 50* 
Note: *Only two participants, therefore $50 \%$ is consensus on non $100 \%$ items by default

It is worth noting that, even though round two only had two participants, the items ranked five (Agree) or six (Strongly agree) by both of the participants, are fairly consistent. Out of the 35 skills discovered from round one, only two items reached $100 \%$ consensus with a rank of six (Strongly agree) by both experts. Seven of the 35 items, including the two top ranked, achieved a rank of five (Agree) or six (Strongly agree). Being that round three was removed from the survey, the researchers concluded that any items that had a score of at least five (Agree) by both participants, was considered to reach consensus as the most important within the score of $75 \%$ or higher (Table 4.4).

Table 4.4

Items Rated 5 (agree) or

6 (strongly agree)

$(n=2)$

$\begin{array}{llll}\text { Teacher/Technical Skills } & \text { Teacher } 1 \text { Rating Teacher } 2 \text { Rating } \quad \% \text { Agreement }\end{array}$

Measuring

6

6

100

Safety (Technical)

6

6

100

Safety (Teacher)

6

5

50

Supervision

6

5

50

Tool Usage (Teacher)

5

5

100 
Oxy-Acetylene Torch

Carpentry

Note: Only two participants in round two
5

100

100

\section{Round Three}

The third round of the survey was to consist of the top rated $(\leq 75 \%)$ skills from round two so that they could again be rated to achieve total consensus. However, since only two teachers participated in round two, the researchers felt as if a third round would be unnecessary. The third round could have only been sent to the two participants from the previous round and the researchers concluded that consensus had already been reached. 


\section{CHAPTER V}

\section{CONCLUSION}

\section{Discussion/Implications}

The main objectives of an SBAE mechanics program, just like all SBAE programs, is to create competent, skilled, life-long learners who will be successful after graduation (Roberts \& Ball, 2009). Research has been done (McKim \& Saucier, 2011; Saucier et. al., 2014) to show the importance of safety and management skills in the shop. Where the research is incomplete is the importance of the content being taught. This study serves to fill this gap in information. By using the snowball sampling method, the panel was deemed experts in agricultural mechanics by their peers. The Delphi method serves to make sure the skills found to be most important are indeed considered important by consensus from the group.

This study provided a list of 27 technical and teacher skills deemed important by West Virginia SBAE mechanics teachers. The skills provided by the panel demonstrate that there is a plethora of knowledge and skills that agriculture mechanics teachers need to be fluent in. However, a lot of emphasis was placed on teacher skills, such as safety and management; that does not mean that this researcher believes that those skills are any more important than other skills on the list. To truly be an effective SBAE mechanics teacher, the teacher has to be well-rounded and well-versed in all skills and knowledge detailed in this study. Johnson \& Schumacher (1989) note that competencies in knowledge and skills is imperative to in-service and pre-service SBAE teachers success. 
This study serves as a great foundation for future research in the area of knowledge and skills. It could potentially have an impact on West Virginia state content standards in what skills and areas of mechanical knowledge should be taught in high school programs and in pre-service programs. It could also go even further into looking at how more emphasis should be placed on the teaching of mechanical skills within pre-service teacher preparation programs. Research has shown that first year SBAE mechanics teachers rate low on efficacy related to agriculture mechanics (Burris et al., 2005). The results of this study suggest that West Virginia agriculture mechanics teachers place a high importance on safety and basic skills. Both safety in the technical category and safety in the teacher category received high scores, which means that West Virginia SBAE teachers place a high importance on teaching safety to the students and themselves knowing proper safety techniques in the shop. Previous research has shown that SBAE teachers around the country place proper safety procedures in a high regard (McKim \& Saucier, 2011; Saucier et al., 2014). Therefore, we can infer that safety is a top priority to all SBAE teachers.

The interesting fact is that, outside of safety, the SBAE teachers in this study also place a high regard on aspects of agriculture mechanics such as measuring, tool usage, carpentry, and Oxy-Acetylene use. These skills tend to fall into the more basic side of skills taught and historically, have always been the majority of teaching points (Hainline \& Wells, 2019). There can be many assumed factors as to why the SBAE teachers in this study placed these items as they did. An assumption can be made that perhaps they don't have the proper facilities to expand knowledge areas, or perhaps they don't have the funding to incorporate new and better 
technology into their program. Whatever the reason may be, the answer will not be known without further investigation.

The fact that the typical teacher for this study was a middle aged male with 12-17 years of teaching experience also could have influenced the ranking of topics in this study. It is reasonable to predict that these teachers were agriculture education students in the 1980's and their own time in the classroom has influenced their decisions as teachers. Research has proven that current agriculture mechanics teachers show a correlation between the content areas they teach and the areas they were taught as students (Rasty et al., 2017). As these older teachers retire and new teachers take their places, the landscape of agriculture mechanics will inevitably change. One thing that holds true and will continue to affect SBAE mechanics programs is the presence of the agriculture industry and other skill based industries (Roberts \& Ball, 2009).

\section{Recommendations}

This study sought to gain information in hopes that the curriculum of undergraduate teacher prep programs can be shifted to fit a heavier focus on skill acquisition and how to teach those skills. The overall purpose is to find the information needed in order to create teachers who are competent and effective enough to teach successful SBAE mechanics programs. From this study, the researcher recommends that the scope should be increased to include not only the northern mid-atlantic region, but other regions around the country. It would be interesting to see how the skills deemed important could change from state to state. Researchers could see some of the same skills and knowledge areas remain the same. Another recommendation is to build a larger potential participant list. This study started with 15 possible candidates, then had four in 
the first round and eventually dwindled to two in the second. The loss of the third round, while unable to be avoided in this study, would have proven to be instrumental in finding a true consensus on the skills in this study. Therefore, a larger candidate pool could have helped to prevent this issue by ensuring larger participation. It is the recommendation of this researcher that this study should be enhanced and reproduced to identify the technical and teacher skills needed by in-service SBAE teachers to successfully teach an agricultural mechanics course. 


\section{References}

Associated Press. (2021, February 18). Toyota to increase assembly capacity at West Virginia plant.

https://www.whsv.com/2021/02/18/toyota-to-increase-assembly-capacity-a t-west-virginia-plant/

Alvaro, S. (2019, April 8). How Many Oil and Gas Jobs Are There in W.VA.? It's Surprisingly Hard to Say. https:/www.wvpublic.org/news/2019-04-08/how-many-oil-and-gas-jobs-a re-there-in-w-va-its-surprisingly-hard-to-say

Brannon, J. (2018, November 9). Agriculture in West Virginia. West Virginia Executive.

https://www.wvexecutive.com/agriculture-west-virginia/\#: :text=West $\% 2$ 0Virginia $\% 20$ was $\% 20 \mathrm{a} \% 20$ hot $\% 20$ bed $\% 20$ of $\% 20$ agriculture,climate $\% 20$ and $\% 20$ changing $\% 20$ markets $\%$ E2\%80\%94the $\% 20$ agriculture $\% 20$ industr y\%20dwindled\%20greatly.

Burris, S., Robinson, J. S., \& Terry, R. (2005) Preparation of Pre-Service Teachers in Agricultural Mechanics. Journal of Agriculture Education, 46(3), 23-34.

DeKeyser, R., VanPatten, B., \& Williams, J. (2007). Skill acquisition theory. Theories in second language acquisition: An introduction, 97113.

Dewey, J. (1938). Experience and education 
Dreyfus, S. E. (2004). The five-stage model of adult skill acquisition. Bulletin of science, technology \& society, 24(3), 177-181.

Drost, E. A. (2011). Validity and reliability in social science research. Education Research and perspectives, 38(1), 105-123.

Eck, C. J., \& Edwards, M. C. (2019). Teacher Shortage in School-Based, Agricultural Education (SBAE): A Historical Review. Journal of Agricultural Education, 60(4).

Goodman, L. (1961). Snowball Sampling. The Annals of Mathematical Statistics, 32(1), 148-170.

Hainline, M. S., \& Wells, T. (2019). Identifying the Agricultural Mechanics Knowledge and Skills Needed by Iowa School-based Agricultural Education Teachers. Journal of Agricultural Education, 60(1).

Heale, R., \& Twycross, A. (2015). Validity and reliability in quantitative studies. Evidence-based nursing, 18(3), 66-67.

Hillison, J. (1987). Agricultural Teacher Education Preceding the Smith-Hughes Act. Journal of the American Association of Teacher Educators in Agriculture, 28(2), 8-17.

Hyslop-Margison, E. J. (1999). An Assessment of the Historical Arguments in Vocational Education Reform.

Johnson, D. M. \& Schumacher, L. G. (1989). Agricultural Mechanics Specialists Identification and Evaluation of Agricultural Mechanics Laboratory Management Competencies: A Modified Delphi Approach. Journal of Agriculture Education, 30(3), 23-28. 
Kotrlik, J. W. \& Drueckhammer, J. W. (1987). The Importance of Selected External Factors Programmatic Components in Planning Vocational Agriculture Programs. Journal of the American Association of Teacher Educators in Agriculture, 28(4), 26-31.

McKim, B. R. \& Saucier, P. R. (2011). Agricultural Mechanics Laboratory Management Professional Development Needs of Wyoming Secondary Agriculture Teachers. Journal of Agriculture Education, 52 (3), 75-86.

National FFA. (2021). Agricultural Education. https://www.ffa.org/agricultural-education/

National Coal Heritage Area \& Coal Heritage Trail. (n.d.). Birth of the Coal Industry. https://coalheritage.wv.gov/coal_history/Pages/Birth-of-the-Industry.aspx\#: :text=The\%2 0West $\% 20$ Virginia $\% 20$ coal $\% 20$ industry $\% 20$ dates $\% 20$ to $\% 20$ the,abundantly $\% 20$ along $\% 2$ 0the\%20banks\%20of\%20the\%20Kanawha\%20River.

Newcomb, L. H. (1974). Role of agricultural educators in competency-based teacher education. Journal of the American Association of Teacher Educators in Agriculture.

Oomes, F. W. \& Jurshak, S. (1978). Lecture vs. Laboratory Instruction in Agricultural Mechanics. Journal of the American Association of Teacher Educators in Agriculture, $19(3), 31$.

Rasty, J., Anderson, R. G., \& Paulsen, T. H. (2017). How the Quantity of Agricultural Mechanics Training Received at the Secondary Level Impact Teacher Perceived Importance of Agricultural Mechanics Skills. Journal of Agricultural Education, 58(1), 36-53.

Roberts, T. G., \& Ball, A. L. (2009). Secondary Agricultural Science as Content and Context for Teaching. Journal of Agricultural Education, 50(1), 81-91. 
Saucier, P. R., Vincent, S. K., \& Anderson, R. G. (2014). Laboratory Safety Needs of Kentucky School-Based Agricultural Mechanics Teachers. Journal of Agriculture Education, 55(2), 184-200.

Shoulder, C. W., Myers, B. E. (2012). Teachers' Use of Agricultural Laboratories in Secondary Agricultural Education. Journal of Agriculture Education, 53(2), 124-138.

Shoulders, C. W., \& Toland, H. (2017). Millennial and Non-Millennial Agriculture Teachers' Current and Ideal Emphasis on the Three Components of the Agricultural Education Program. Journal of Agricultural Education, 58(1), 85-101.

Steffes, T. L. (2020, July 24). Smith-Hughes Act. Encyclopedia Britannica. https://www.britannica.com/topic/Smith-Hughes-Act

Torres, R. M., Ulmer, J. D., \& Aschenbrener, M. S. (2008). Workload Distribution among Agriculture Teachers. Journal of Agricultural Education, 49(2), 75-87.

Twenter, J. P., \& Edwards, M. C. (2017). Facilities in School-Based, Agricultural Education (SBAE): A Historical Inquiry. Journal of Agricultural Education, 58(3), 275-292.

TWI. (n.d.). What is Welding?- Definition, Processes, and Types of Welds. https://www.twi-global.com/technical-knowledge/faqs/what-is-welding

Wells, T., Perry, D. K., Anderson, R. G., Shultz, M. J., \& Paulsen, T. H. (2013). Does Prior Experience in Secondary Agricultural Mechanics Affect Pre-Service Agricultural Education Teachers' Intentions to Enroll in Post-Secondary Agricultural Mechanics Coursework?. Journal of Agricultural Education, 54(4), 222-237.

West Virginia Coal Association. (2010). The State of Coal. https://www.wvcoal.com/education-2/state-of-coal 
West Virginia Department of Commerce. (n.d.). Thriving Industries: Agriculture.

https://westvirginia.gov/industries/agriculture/

West Virginia Division of Forestry. (n.d.). Logging in West Virginia.

https://wvforestry.com/logging/

West Virginia FFA Association. (2019). Agriculture Education, West Virginia's Fastest Growing CTE Program. http://www.wvffa.net/ffa-factsheet_18-19.pdf

West Virginia State Museum Education (n.d.). The Timber Industry.

http://wvstatemuseumed.wv.gov/Timber\%20industry.html

Woudenberg, F. (1991). An Evaluation of Delphi. Technological Forecasting and Social Change, $40,131-150$. 
APPENDICES 
APPENDIX A

IRB APPROVAL LETTER 


\section{West VirginiaUniversity.}

\section{OFFICE OF HUMAN RESEARCH PROTECTIONS}

886 Chestnut Ridge Road Morgantown, WV 26506

Acknowledgement of Exemption

$12 / 17 / 2020$

To: Haley Rosson

From: WVU Office of Research Integrity \& Compliance

Protocol Type: Exempt

Approval Date: 12/17/2020

Submission Type: Initial

Expiration Date:

$12 / 16 / 2025$

Funding: N/A

WVU Protocol \#: 2011169940

Protocol Title: Identifying the Technical and Teacher Skills Needed by In-Service Teachers to Effectively Teach an Agricultural Mechanics Course in West Virginia. The West Virginia University Institutional Review Board has reviewed your submission of Exempt protocol 2011169940. Additional details regarding the review are below:

- This research study was granted an exemption because this

(i) Research involves Benign Behavioral Interventions through verbal, written responses, (including data entry or audiovisual recording) from adult subject who prospectively agrees and ONE of following met: A. Recorded information cannot readily identify the subject (directly or indirectly/linked) B. Any disclosure of responses outside of the research would NOT reasonably place subject at risk (criminal, civil liability, financial, employability, educational advancement, reputation) C. Information is recorded with identifiers \& IRB conducts Limited Review 104(d)(3)(i)

The following documents were reviewed and approved for use as part of this submission. Only the documents listed below may be used in the research. Please access and print the files in the Notes \& Attachments section of your approved protocol.

- Thesis Cover letter.docx 
- Thesis Survey (2).docx

Protocol \#: 2011169940

Phone: 304-293-7073

FWA: 00005078

Fax: 304-293-3098

IORG: 0000194

Email: IRB@mail.wvu.edu

WVU IRB acknowledgement of protocol 2011169940 will expire on 12/16/2025.

If the study is to continue beyond the expiration date, a renewal application must be submitted no later than two (2) weeks prior to expiration date. It is your responsibility to submit your protocol for renewal.

Once you begin your human subjects research, the following regulations apply:

1. Unanticipated or serious adverse events and/or side effects encountered in this research study must be reported to the IRB within five (5) days, using the Notify IRB action in the electronic protocol.

2. Any modifications to the study protocol should be submitted only if there will be an increase in risk to subjects accompanying the proposed change(s).

3. You may not use a modified information sheet until it has been reviewed and acknowledged by the WVU IRB prior to implementation.

The Office of Research Integrity and Compliance will be glad to provide assistance to you throughout the research process. Please feel free to contact us by phone, at 304.293.7073 or by email at IRB@mail.wvu.edu.

\section{Sincerely,}


APPENDIX B

SURVEY COVER LETTER 
Dear West Virginia Secondary Agricultural Educators,

As a current West Virginia Secondary Agricultural Educator, you are key in understanding what technical agricultural mechanics and teacher skills are needed by agricultural educators in West Virginia public schools. Research shows agricultural mechanics is an integral part of the full agriculture education model. However, most new in-service teachers are lacking in technical skills needed to be effective agricultural mechanics teachers. To ensure that West Virginia agriculture educators are prepared to provide agricultural mechanics instruction we hope that you will participate in this study.

I am Coleton Payne, a graduate student in the Department of Agricultural and Extension Education. Under the direction of my advisor, Dr. Haley N. Rosson, I am conducting research to explore and document what technical and teacher skills are needed by West Virginia Agriculture Mechanics teachers to be effective instructors. The results will be used to prepare a thesis to partially fulfill the requirements for a Master of Science degree in Agricultural and Extension Education. The results will also be shared with West Virginia Agriculture teachers and other Agricultural Education Teacher Preparation programs through research presentations.

We are contacting West Virginia secondary Agriculture Teachers for this study. The results will provide information on the skills deemed necessary by the panel to effectively teach an agricultural mechanics course. Please take a few moments and share your opinions with us.

Participation in this research study is completely voluntary and all information you provide will be confidential. The research method is a modified Delphi approach that will consist of three rounds. Each round should only take about ten minutes to complete, and your response to each round is crucial to the success of the study. Each round will start on Monday and end on Friday of the same week. Data analysis will occur over the weekend in preparation for the next round of the survey. During your participation, you may skip any question you are not comfortable answering and you can stop at any time. Survey results will be reported in a summary format and individual responses will not be identifiable.

The Institutional Review Board (IRB) at West Virginia University has acknowledged this study. If you have any questions or concerns about completing the questionnaire or about being a participant in this study, you may contact either myself at ctpayne@mix.wvu.edu, or my advisor Dr. Haley Rosson at haley.rosson@mail.wvu.edu.

Please click the highlighted link below to access the study. Thank you in advance for your assistance with this research effort. We sincerely appreciate your participation.

Sincerely, 
APPENDIX C

SURVEY ROUND ONE 
Identifying the Skills Needed by Agricultural Education Teachers

Start of Block: Block 1

Q8 Welcome to this survey, which will determine the skills deemed necessary to effectively teach an agricultural mechanics course in the state of West Virginia. This round of the survey will take 10-20 minutes to complete. Please complete the survey in its entirety. This survey is being administered to a group of agricultural mechanics teachers from across the state of West Virginia. Privacy will be protected and confidentiality will be maintained throughout the duration. Only a qualified research team will have access to the responses. If you have any questions, feel free to email Cole Payne at ctpayne@mix.wvu.edu. To begin the survey, click the arrow below.

End of Block: Block 1

Start of Block: Default Question Block

Q1 What technical agricultural mechanics knowledge and skills (i.e. aspects of welding, woodwork, mechanics, etc.) are needed by agricultural education teachers to successfully teach agricultural mechanics courses in West Virginia? (list as many as you think appropriate)

Q2 What laboratory management "teacher skills" (i.e. knowing how to use power tools, setting up an oxy-acytylene torch, changing blades on a saw, etc.) are needed by agricultural education 
teachers to successfully teach an agricultural mechanics course in West Virginia? (list as many as you think appropriate)

End of Block: Default Question Block

Start of Block: Block 3

Q3 How many years have you taught agricultural mechanics?

$0-5$ years teaching (1)

6-11 years teaching (2)

12-17 years teaching (3)

$17+$ years teaching (If yes, please write exact years below) (4)

Q4 What is your gender?

Male (1)

Female (2) 
Q5 What is your age?
20-29 years of age (1)
$30-39$ years of age (2)
40-49 years of age (3)
$50+$ years of age (4)

Q6 Briefly describe the type of laboratory you teach/taught in? (i.e. wood shop, metal shop, etc.)

Q7 Provide some examples of your agricultural mechanics teaching experience. (i.e. training CDE teams, events, projects, etc.)

\section{End of Block: Block 3}


APPENDIX D

SURVEY ROUND TWO 
Identifying the Skills needed by Agricultural Mechanics Educators in the State of West Virginia ptll

\section{Start of Block: Default Question Block}

Q1 Welcome to round II of this survey, which will ask you to rate the skills you previously deemed necessary for agriculture mechanics teachers in the state of West Virginia. This round of the survey will take 5-10 minutes to complete. Please complete the survey in its entirety. This survey is being administered to a group of agricultural mechanics teachers from across the state of West Virginia. Privacy will be protected and confidentiality will be maintained throughout the duration. Only a qualified research team will have access to the responses. If you have any questions, feel free to email Cole Payne at ctpayne@mix.wvu.edu. To begin the survey, click the arrow below.

End of Block: Default Question Block

Start of Block: Block 1

Q2 Please rate each skill. 1 is the lowest, 4 is moderate, and 6 is the highest.

1 (1) 2 (8) $3(2) \quad 4(3) \quad 5(4) \quad 6(5)$

Oxy-Actylene Operation (1) o

0

0

0

0

o

SMA

MIG Welding (3)

0

0

0

0

O

TIG Welding (4)

0

0

0

0

0

Metal Fabrication (5) o

0

0

0

0

o

Diesel Engine Repair (6)

0

o

0

0

0

Gas Engine Repair (7)

o

Electrical Wiring (8) o

0

0

0

0

0

Electrical Principals (9)

0

0

0

0

0 


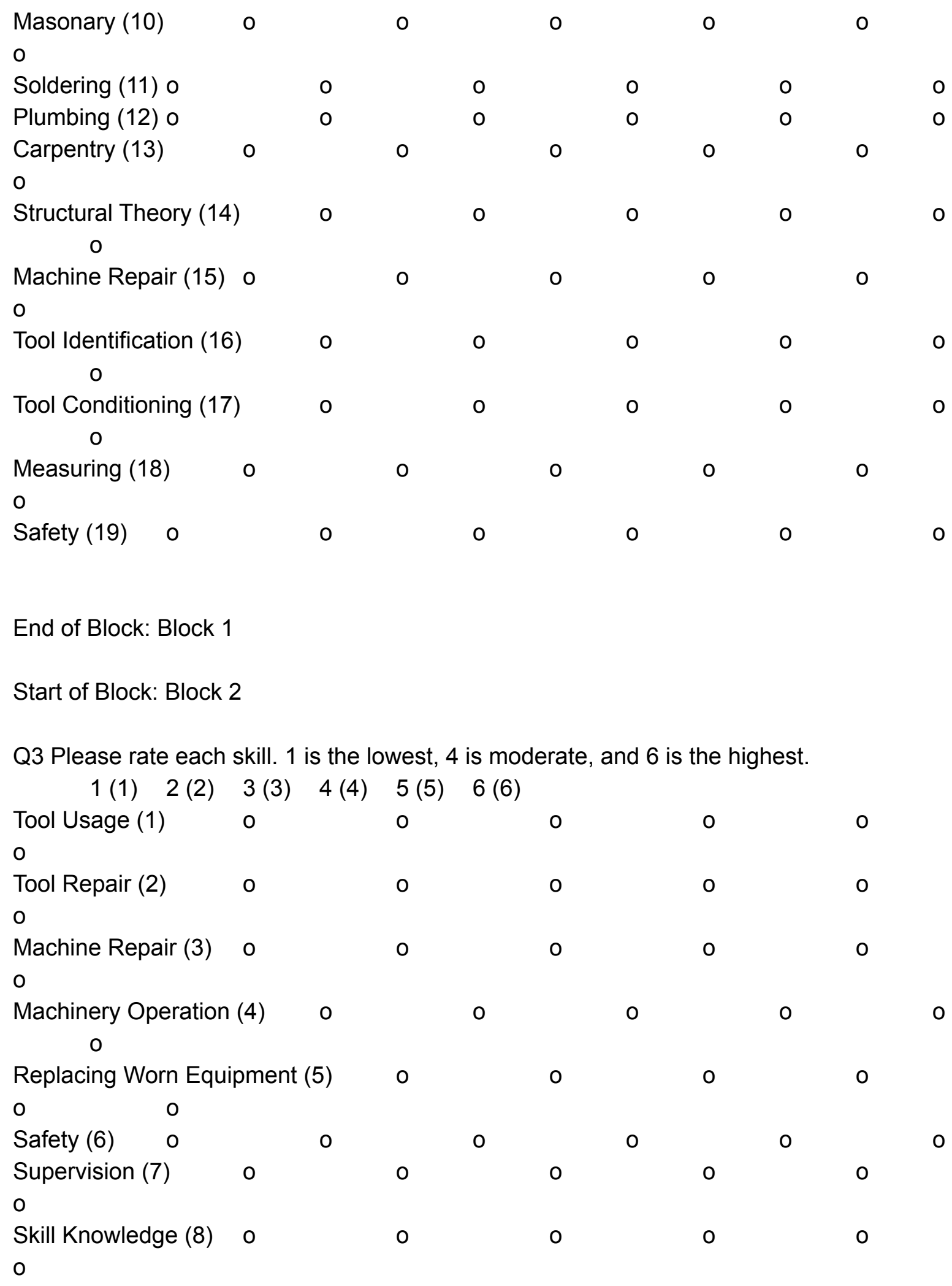

End of Block: Block 2 